OPEN ACCESS

Edited by:

Ajay Sharma,

Chapman University, USA

Reviewed by:

Carmela Parenti,

University of Catania, Italy

Attila Szabo,

University of Oslo, Norway

*Correspondence:

Víctor Fernández-Dueñas

vfernndez@ub.edu

Francisco Ciruela

fciruela@ub.edu

Specialty section:

This article was submitted to

Experimental Pharmacology and Drug

Discovery,

a section of the journal

Frontiers in Pharmacology

Received: 27 October 2016

Accepted: 04 January 2017

Published: 17 January 2017

Citation:

Fernández-Dueñas V, Burgueño J and

Ciruela F (2017) Exploring

Drug-Receptor Interaction Kinetics:

Lessons from a Sigma-1 Receptor

Transmembrane Biosensor.

Front. Pharmacol. 8:4.

doi: 10.3389/fphar.2017.00004

\section{Exploring Drug-Receptor Interaction Kinetics: Lessons from a Sigma-1 Receptor Transmembrane Biosensor}

\author{
Víctor Fernández-Dueñas ${ }^{1,2 *}$, Javier Burgueño ${ }^{3}$ and Francisco Ciruela ${ }^{1,2 *}$ \\ 1 Unitat de Farmacologia, Departament Patologia i Terapèutica Experimental, Facultat de Medicina, IDIBELL, Universitat de \\ Barcelona, L'Hospitalet de Llobregat, Barcelona, Spain, ${ }^{2}$ Institut de Neurociències, Universitat de Barcelona, Barcelona, \\ Spain, ${ }^{3}$ Drug Discovery and Preclinical Development, ESTEVE, Barcelona, Spain
}

Keywords: $\sigma_{1}$ receptor, crystal structure, cell surface, FRET, plasma membrane

An important field of study in pharmacology comprises the investigation of drug-target interaction kinetics. Thus, assessing both the lifetime of a drug on its receptor (i.e., drug-target residence time; Copeland, 2016) and the magnitude of drug-mediated receptor activation (i.e., drug efficacy) across the time are critical to understand in vivo pharmacological activity of small-molecule drugs. Of note, while classical in vitro methods view drug-receptor interaction in terms of equilibrium affinity, the residence time model considers the dynamics of receptor conformational rearrangements, which affect drug association and dissociation. Although, classical binding experiments can also address kinetics questions, they are tedious and very time consuming. Accordingly, monitoring drug-receptor interaction dynamics by means of receptor biosensors has become fundamental for understanding how drugs trigger receptor activity over the time. Precisely, in the last years, a number of Fluorescence Resonance Energy Transfer (FRET)-based assays have been developed to accurately display drug-receptor interaction in real time (Lohse et al., 2012). Indeed, one of the most outstanding methods consists of assessing intramolecular conformational rearrangements upon receptor challenge by monitoring intramolecular FRET changes (Vilardaga et al., 2009). Thus, a FRET-based receptor biosensor is built by fusing both donor and acceptor fluorophores to the receptor sequence (Vilardaga et al., 2009). Importantly, a general consensus has prompted to basically attach these molecules (i.e., cyan and yellow fluorescent proteins, CFP and YFP, respectively) intracellularly, this is, in the cytosolic side of the receptor's structure (Figure 1A). Accordingly, when the receptor is activated and a conformational rearrangement occurs the distance and/or orientation of the fluorophores within the receptor biosensor changes and it is possible to monitor FRET changes in real time, thus permitting to finely characterize receptor's activation. Needless to say, although precision is higher than that obtained in classical binding assays, the present biosensors cannot discern between receptors expressed at the cell surface or intracellularly, thus much effort is needed in order to exactly elucidate ligand-receptor kinetics constants.

Within this scenario, we recently developed a dynamic $\sigma 1$ receptor $(\sigma 1 \mathrm{R})$ biosensor able to achieve ligand-specific conformational rearrangements with high temporal resolution (GómezSoler et al., 2014). The $\sigma 1 \mathrm{R}$ gene encodes an endoplasmic reticulum and plasma membrane anchored protein of 223 amino acids, which shows no similarity to any other known mammalian protein receptor but that is quite conserved across species (Vela et al., 2015). The $\sigma 1 \mathrm{R}$ has been lately defined as a ligand-regulated chaperone that is able to interact with a myriad of other proteins including receptors, enzymes or ion channels. For instance, it has been linked to 


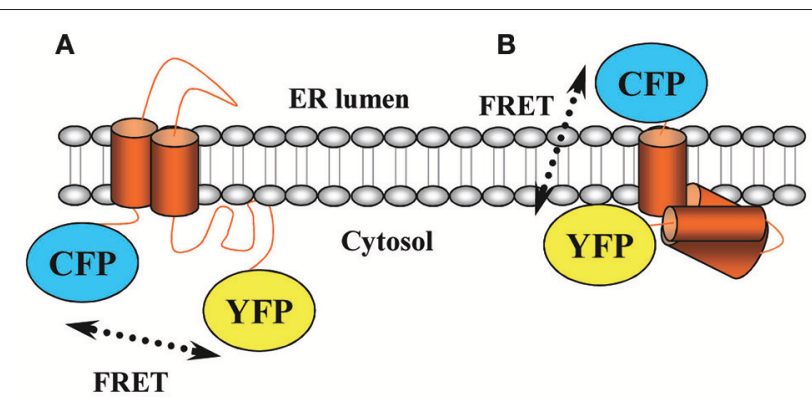

FIGURE 1 | Scheme of the $\sigma 1 R$ biosensor. A schematic diagram illustrating the topology of the $\sigma 1 \mathrm{R}$ as considered before $(\mathbf{A})$ and after $(\mathbf{B})$ its crystallization. ER, endoplasmic reticulum.

serotonin or NMDA receptors, which may be of interest for the management of neurological or neurodegenerative disorders (Nguyen et al., 2015). In fact, this latter topic has recently gained a great interest, thus a number of animal models have been developed to study neuroprotective effects of $\sigma 1 \mathrm{R}$ ligands (Nguyen et al., 2015). Needless to say, a $\sigma 1 \mathrm{R}$-defficient mouse model was developed, which exhibited no overt phenotype in terms of baseline behavior or immune profile (Langa et al., 2003). Hence, the $\sigma 1 \mathrm{R}$ may basically modulate the intracellular signaling evoked by those interacting partners rather than by exerting an action by itself (Romero et al., 2012). Due to the lack of this direct functional effect or signaling by its own, it has been difficult to classify $\sigma 1 \mathrm{R}$ ligands by their intrinsic activity and time-consuming in vivo tests are frequently used to determine the functional characteristics of $\sigma 1 \mathrm{R}$ ligands. Accordingly, we designed a CFP/YFP-tagged $\sigma 1 \mathrm{R}$ aiming to distinguish agonists from antagonists based on the conformational rearrangement engaged. We thus attached CFP and YFP to the N- and Cterminus of the receptor based on the most accepted structural model available, in which both extremes of the receptor faced the cytoplasm (Ruoho et al., 2012). Of note, a few months ago, the crystal structure of the human $\sigma 1 \mathrm{R}$ was finally disclosed (Schmidt et al., 2016). This seminal study revealed that the $\sigma 1 \mathrm{R}$ holds a triangular structure comprising three tightly associated protomers, each with a single transmembrane domain that segregates the $\mathrm{N}$ - and C-terminus of the receptor (Schmidt et al., 2016) (Figure 1B). Indeed, previous biochemical studies also supported the contention that $\sigma 1 \mathrm{R}$ do oligomerize (Gromek et al., 2014; Mishra et al., 2015). Interestingly, the $\sigma 1 \mathrm{R}$ oligomerization status seems to be ligand-dependent, thus while antagonists stabilize high molecular mass oligomers the agonists prompt the dissociation of these complexes (Mishra et al., 2015). Collectively, these results suggest that $\sigma 1 \mathrm{R}$ oligomerization might play a key role in receptor functioning by controlling ligand efficacy (Schmidt et al., 2016).

In view of the $\sigma 1 \mathrm{R}$ molecular structure, we blindly designed a transmembrane biosensor, since we thought that both CFP and YFP were inside the cell while they were really in opposite sides of the cell surface (Figure 1B). Nevertheless, we observed by means of donor recovery after acceptor photo bleaching that there was constitutive intramolecular FRET (Gómez-Soler et al.,
2014). And subsequently, once ascertained that the biosensor retained its essential ligand binding properties we performed real-time FRET, in which the superfusion of $\sigma 1 \mathrm{R}$ agonists or antagonists led to a decrease or increase, respectively, of energy transfer (Gómez-Soler et al., 2014). Since it has been postulated that $\sigma 1 \mathrm{R}$ antagonists are analgesic and agonists preclude opioidmediated pain relief (Prezzavento et al., 2010), we assessed antinociception elicited by $\sigma 1 \mathrm{R}$ ligands in the formalin pain animal model to correlate with the FRET-induced changes. Hence, while $\sigma 1 \mathrm{R}$ antagonists led to a FRET increase and produced analgesia, agonists led to a FRET decrease and did not induce antinociceptive effects (Gómez-Soler et al., 2014).

The development of our $\sigma 1 \mathrm{R}$ biosensor permitted to classify $\sigma 1 \mathrm{R}$ ligands according to its intrinsic activity, since it was possible to correlate FRET changes upon ligand activation with analgesic efficacy. This tool may therefore represent a powerful approach in drug discovery in the intriguing world of the $\sigma 1 \mathrm{R}$. But on the other hand, it may also represent the beginning of a new generation of biosensors able to characterize ligandreceptor kinetics constants with high precision. In such way, as commented above, we blindly developed the first receptor biosensor able to detect intramolecular FRET changes through the cell surface. Needless to say, although scarcely assayed, transmembrane FRET has been previously described; thus, it was demonstrated that energy transfer is possible between fluorophores despite they are segregated by a lipid bilayer (Majoul et al., 2001; Haga et al., 2012). Taken together, data support that conformational receptor rearrangement can be monitored by means of FRET across the plasma membrane. Thus, in order to exclusively target receptors expressed at the cell surface different approaches would be intended. For instance, by substituting the outer-fluorophore (i.e., CFP) by another protein (i.e., O-6-methylguanine-DNA methyltransferase, AGT), which may be selectively labeled when expressed at the plasma membrane (Maurel et al., 2008). Upon these conditions, when challenging the new biosensor with selective ligands, the FRET process would only occur with these receptors expressed at the cell surface, thus permitting to perform the most real-time precise kinetics.

Overall, pharmacologists have explored for a long time the activity of $\sigma 1 \mathrm{R}$ based on structural models that have been finally overruled by the recent elucidation of its structure (Schmidt et al., 2016). The precise knowledge of $\sigma 1 \mathrm{R}$ structure may not only prompt to review a number of previous inaccurate conclusions with direct impact on the $\sigma 1 \mathrm{R}$ pharmacology, but it also may lead to design novel strategies to wholly characterize ligand-receptor interaction kinetics. In conclusion, the delayed discovery of the first transmembrane biosensor may represent a kind of paradigm shift. Hence, after witnessing an apple falling from the tree, a new frontier has been torn down to develop novel tools for studying receptors' pharmacology.

\section{AUTHOR CONTRIBUTIONS}

VF wrote the paper. JB wrote the paper. FC conceived the idea and wrote the paper. 


\section{ACKNOWLEDGMENTS}

This work was supported by MINECO/ISC III (SAF2014-55700-P, PCIN-2013-019-C03-03, and PIE14/00034),

\section{REFERENCES}

Copeland, R. A. (2016). The drug-target residence time model: a 10-year retrospective. Nat. Rev. Drug Discov. 15, 87-95. doi: 10.1038/nrd.2015.18

Gómez-Soler, M., Fernández-Dueñas, V., Portillo-Salido, E., Pérez, P., Zamanillo, D., Vela, J. M., et al. (2014). Predicting the antinociceptive efficacy of $\sigma(1)$ receptor ligands by a novel receptor fluorescence resonance energy transfer (FRET) based biosensor. J. Med. Chem. 57, 238-242. doi: 10.1021/jm40 $1529 \mathrm{t}$

Gromek, K. A., Suchy, F. P., Meddaugh, H. R., Wrobel, R. L., LaPointe, L. M., Chu, U. B., et al. (2014). The oligomeric states of the purified sigma-1 receptor are stabilized by ligands. J. Biol. Chem. 289, 20333-20344. doi: 10.1074/jbc.M113.537993

Haga, Y., Ishii, K., Hibino, K., Sako, Y., Ito, Y., Taniguchi, N., et al. (2012). Visualizing specific protein glycoforms by transmembrane fluorescence resonance energy transfer. Nat. Commun. 3, 907. doi: 10.1038/ncomms1906

Langa, F., Codony, X., Tovar, V., Lavado, A., Giménez, E., Cozar, P., et al. (2003). Generation and phenotypic analysis of sigma receptor type I $(\sigma 1)$ knockout mice. Eur. J. Neurosci. 18, 2188-2196. doi: 10.1046/j.1460-9568.2003.02950.x

Lohse, M. J., Nuber, S., and Hoffmann, C. (2012). Fluorescence/bioluminescence resonance energy transfer techniques to study G-protein-coupled receptor activation and signaling. Pharmacol. Rev. 64, 299-336. doi: 10.1124/pr.110.004309

Majoul, I., Straub, M., Hell, S. W., Duden, R., and Söling, H. D. (2001). KDEL-cargo regulates interactions between proteins involved in COPI vesicle traffic: measurements in living cells using FRET. Dev. Cell 1, 139-153. doi: 10.1016/S1534-5807(01)00004-1

Maurel, D., Comps-Agrar, L., Brock, C., Rives, M. L., Bourrier, E., Ayoub, M. A., et al. (2008). Cell-surface protein-protein interaction analysis with time-resolved FRET and snap-tag technologies: application to GPCR oligomerization. Nat. Methods 5, 561-567. doi: 10.1038/nmeth.1213

Mishra, A. K., Mavlyutov, T., Singh, D. R., Biener, G., Yang, J., Oliver, J. A., et al. (2015). The sigma-1 receptors are present in monomeric and oligomeric forms in living cells in the presence and absence of ligands. Biochem. J. 466, 263-271. doi: 10.1042/BJ20141321

Nguyen, L., Lucke-Wold, B. P., Mookerjee, S. A., Cavendish, J. Z., Robson, M. J., Scandinaro, A. L., et al. (2015). Role of sigma-1 receptors in neurodegenerative
IWT (SBO-140028), and Fundació la Marató de TV3 (Grant 20152031) to FC. Also, FC and VF belong to the "Neuropharmacology and Pain" accredited research group (Generalitat de Catalunya, 2014 SGR 1251). diseases. J. Pharmacol. Sci. 127, 17-29. doi: 10.1016/j.jphs.2014. 12.005

Prezzavento, O., Campisi, A., Parenti, C., Ronsisvalle, S., Aricó, G., Arena, E., et al. (2010). Synthesis and resolution of cis-( \pm )-methyl $(1 R, 2 S / 1 S$, 2R)-2-[(4-hydroxy-4-phenylpiperidin-1-yl)methyl]-1-(4-methylphenyl)cyclopropanecarboxylate $[( \pm)$-PPCC)]: new $\sigma$ receptor ligands with neuroprotective effect. J. Med. Chem. 53, 5881-5885. doi: 10.1021/jm100116p

Romero, L., Zamanillo, D., Nadal, X., Sánchez-Arroyos, R., Rivera-Arconada, I., Dordal, A., et al. (2012). Pharmacological properties of S1RA, a new sigma-1 receptor antagonist that inhibits neuropathic pain and activity-induced spinal sensitization. Br. J. Pharmacol. 166, 2289-2306. doi: 10.1111/j.1476-5381.2012.01942.x

Ruoho, A. E., Chu, U. B., Ramachandran, S., Fontanilla, D., Mavlyutov, T., and Hajipour, A. R. (2012). The ligand binding region of the sigma-1 receptor: studies utilizing photoaffinity probes, sphingosine and N-alkylamines. Curr. Pharm. Des. 18, 920-929. doi: 10.2174/138161212799436584

Schmidt, H. R., Zheng, S., Gurpinar, E., Koehl, A., Manglik, A., and Kruse, A. C. (2016). Crystal structure of the human $\sigma 1$ receptor. Nature 532, 527-530. doi: 10.1038/nature17391

Vela, J. M., Merlos, M., and Almansa, C. (2015). Investigational sigma-1 receptor antagonists for the treatment of pain. Expert Opin. Investig. Drugs 24, 883-896. doi: $10.1517 / 13543784.2015 .1048334$

Vilardaga, J.-P., Bünemann, M., Feinstein, T. N., Lambert, N., Nikolaev, V. O., Engelhardt, S., et al. (2009). GPCR and G proteins: drug efficacy and activation in live cells. Mol. Endocrinol. 23, 590-599. doi: 10.1210/me. 2008-0204

Conflict of Interest Statement: The authors declare that the research was conducted in the absence of any commercial or financial relationships that could be construed as a potential conflict of interest.

Copyright (c) 2017 Fernández-Dueñas, Burgueño and Ciruela. This is an open-access article distributed under the terms of the Creative Commons Attribution License (CC $B Y)$. The use, distribution or reproduction in other forums is permitted, provided the original author(s) or licensor are credited and that the original publication in this journal is cited, in accordance with accepted academic practice. No use, distribution or reproduction is permitted which does not comply with these terms. 